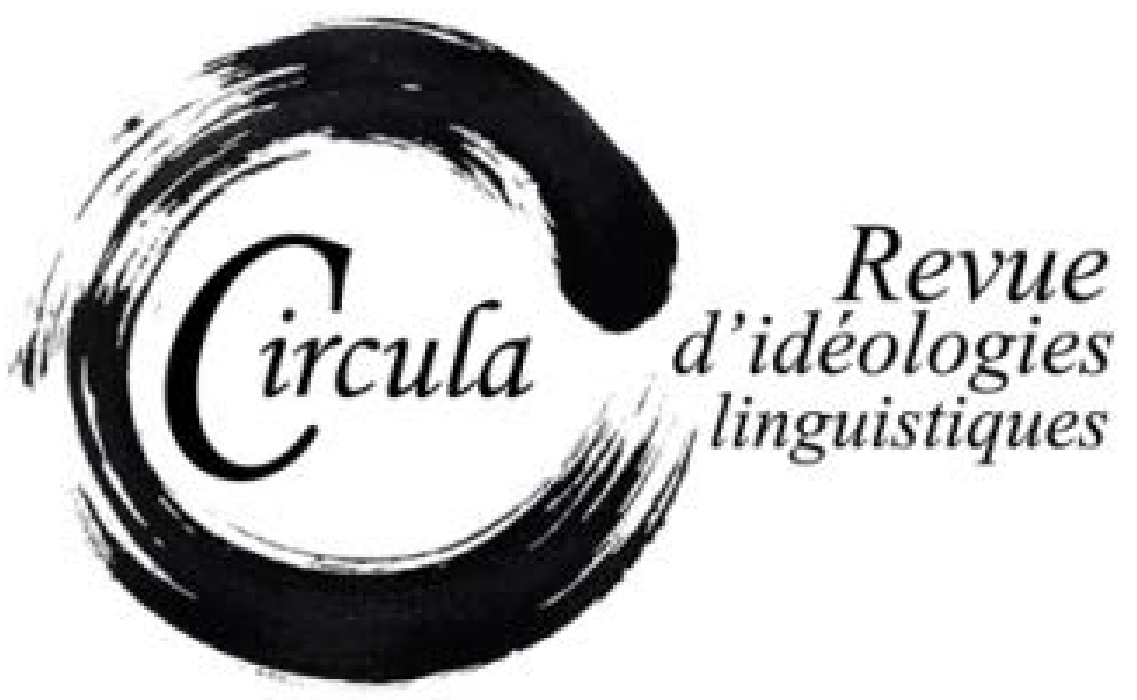

TITRE: IDEOLOGíAS LINGÜÍSTICAS EN EL “DIÁLOgO SEMANAL CON LOS LECTORES” DEL DIARIO ARGENTINO LANACIÓN

Auteur(s): Mariana di Stefano, Universidad de Buenos Aires \& María Cecilia Pereira, UniversiDAD DE BUENOS AIRES

ReVue: CiRCULA, NUMÉRO 2, PAGES 161-175

ISSN: 2369-6761

DiRecteurs: Wim RemySen et SABINE SchWARZE

URI: HTTP://HDL.HANDLE.NET/11143/7988

DOI: $10.17118 / 11143 / 7988$ 


\title{
Ideologías lingüísticas en el "Diálogo semanal con los lectores" del diario argentino La Nación
}

\author{
Mariana di Stefano, Universidad de Buenos Aires \\ marianadist@gmail.com
}

María Cecilia Pereira, Universidad de Buenos Aires ceciliapereira@arnet.com.ar

\begin{abstract}
Resumen: El artículo analiza las ideologías lingüísticas dominantes en una sección del diario argentino La Nación titulada "Diálogo con los lectores", entre 2004 y 2009. El análisis permitió registrar continuidades ideológicas con las tradiciones gramaticales que acompañaron la constitución de diferentes imaginarios sobre la lengua, cristalizadas en las llamadas "gramáticas de Estado" y "gramáticas particulares". Así, los lectores, con una ideología más próxima a la de las gramáticas de Estado, exhiben una tendencia fuertemente prescriptiva, valoradora de una norma única y condenatoria de todo desvío. Por otra parte, el medio en sus respuestas evidencia una ideología crítica de la centralidad y unicidad de la norma, cercana al ideario de las gramáticas particulares, sensible a ciertas formas estabilizadas por el uso del lenguaje como los regionalismos y las variedades dialectales americanas.
\end{abstract}

Palabras clave: ideologías lingüísticas; gramáticas particulares; gramáticas de Estado; comunidad mediática; diario La Nación

\begin{abstract}
This article analyses recurrent language ideologies in a section of the Argentine journal $L a$ Nación entitled "Dialog with readers", between 2004 and 2009. The analysis allowed to register the ideological continuities with grammatical traditions that accompanied the constitution of different representations about language, crystallized in the so-called "grammars of State" and "particular grammars". Thus, readers, whose ideology is closer to that of the grammars of State, exhibit a strongly prescriptive tendency, that privileges a single standard norm and condemns any deviation. On the other hand, in its replies, the journal evidences a critical ideology of centrality and uniqueness of the norm, close to the ideology of the particular grammars, sensitive to certain forms stabilized by the use of language as regionalisms and American dialectal varieties.
\end{abstract}

Keywords: language ideologies; particular grammars; grammars of State; media community; La Nación newspaper 


\section{Introducción}

El diario argentino La Nación contó desde el año 1998 con una sección titulada "Diálogo semanal con los lectores" destinada privilegiadamente a la reflexión sobre distintos aspectos del uso de la lengua. Este trabajo tiene como objetivo analizar esa sección entre los años 2004 y 2009, entendiendo que a través de ella el medio lleva a cabo una intervención glotopolítica. El período que seleccionamos corresponde a una segunda etapa de la sección. La primera etapa, entre 1998 y 2004, estuvo a cargo del periodista Octavio Hornos Paz, una figura destacada del diario, que llegó a ser su Secretario General de Redacción.

Esa primera etapa tuvo como finalidad abrir un espacio para que los lectores escribieran sobre el diario mismo; como señaló incluso Hornos Paz en su primera columna, para que "ayuden a perfeccionarlo", invitándolos a comentar las notas publicadas, ya fuera en cuanto a la claridad en la redacción como en cuanto a cuestiones relativas a la ética periodística. A diferencia de la sección Carta de Lectores, en la que estos no reciben respuesta de la redacción, en este espacio designado "Diálogo", los comentarios de los lectores eran respondidos directamente por el periodista. La aparición de esta sección no está desvinculada de la publicación un año antes, en 1997, del Manual de Estilo y Ética Periodística del diario La Nación, en el marco de un amplio y extendido proceso de intervención sobre la regulación del lenguaje por parte de la esfera privada, como grandes medios periodísticos, editoriales, entre otros ${ }^{1}$. Explicitadas las normas que orientarían la labor periodística en el Manual, el diario invita a que los lectores controlen el cumplimiento de los principios que el mismo diario declama.

Tras la muerte de Hornos Paz, en el año 2004, la sección quedó a cargo de la Profesora Lucila Castro, presentada por el diario como una ex profesora de la Facultad de Filosofía y Letras de la Universidad de Buenos Aires y de una trayectoria de más de 20 años en el diario mismo. La característica de esta segunda etapa es que ya los comentarios de los lectores y las respuestas de la Prof. Castro aluden casi con exclusividad a cuestiones del lenguaje: se señalan errores (léxicos, gramaticales, ortográficos), los lectores plantean dudas sobre usos correctos, o se quejan² de las "deformaciones" de la lengua que identifican en primer lugar en el diario, pero también en otros contextos.

Nuestro objetivo es identificar ideologías lingüísticas en ese espacio discursivo, tanto en las intervenciones de los lectores como en las respuestas que ofrece el medio. El concepto de ideología lingüística tiene su origen en la reflexión proveniente de la Antropología Lingüística norteamericana de los años ‘90 que lo aborda en su dimensión cultural. Uno de sus representantes más importantes, Paul Kroskrity (2000: 8-21), las concibe como una percepción del lenguaje y del discurso producto

1. Ver al respecto el estudio sobre los manuales de estilo de los diarios argentinos de la década de los ' 90 , realizado por Arnoux, Blanco y di Stefano (1999).

2. La actitud de los lectores puede relacionarse con la "complaint tradition" o "tradición de la queja" analizada por Milroy y Milroy (1999: 30-35). 
de los intereses de un grupo cultural o social específico, cuya función es mediar entre las estructuras sociales y los usos del lenguaje, al orientar las opciones lingüísticas de los hablantes.

Desde una perspectiva glotopolítica, Arnoux (2000; 2008; 2013) señala que las ideologías lingüísticas sostienen y orientan las intervenciones sobre el lenguaje que realizan distintos grupos sociales a través de las cuales participan en la instauración, reproducción o transformación de entidades políticas, relaciones sociales y estructuras de poder. Al referirse a la ideología lingüística, Arnoux (2012) la define como:

[...] un sistema de representaciones sociolingüísticas, es decir de aquellas que se refieren a objetos lingüísticos (lenguas, variedades, hablas, acentos, registros, modos de leer o de escribir) y que implican evaluaciones sociales de esos objetos y de los sujetos con los que se los asocia. Dan lugar, entre otros, a actitudes, estereotipos u opiniones y pueden ser reconocidas no sólo en discursos verbales (textos normativos o juicios de hablantes, por ejemplo) sino también en imágenes mediáticas y en las prácticas en las que los interlocutores negocian sus identidades sociales. (Arnoux, 2012: 165-166)

Por su parte, del Valle (2007), que destaca la articulación entre las ideologías lingüísticas y las "formaciones culturales, políticas y/o sociales específicas", señala la función naturalizadora de las ideologías lingüísticas, cuyo efecto normalizador queda apuntalado en el sentido común.

A continuación, presentamos una breve información sobre el diario La Nación, que consideramos necesaria para contextualizar los discursos que publica. Y destacamos que, por tratarse de un diario, conforma lo que Beacco (1999: 14) denomina una "comunidad discursiva mediática". Estas se caracterizan, según el autor, por organizar un "mercado de textos", por establecer jerarquías discursivas (al igual que las comunidades de dominancia económica) y por ser productoras y difusoras de valores, opiniones y creencias (al igual que las comunidades discursiva con dominancia ideológica).

\section{El diario La Nación}

El diario La Nación es hoy el principal diario conservador de la Argentina, que a lo largo de su historia ha privilegiado las voces y puntos de vista de la oligarquía agropecuaria, de las élites empresariales, de la iglesia católica y de las fuerzas armadas. Fue fundado el 4 de enero de 1870 por Bartolomé Mitre, una figura protagónica de lo que fue la organización del estado-nación argentino y de la expansión hegemónica de la burguesía liberal, en la segunda mitad del siglo XIX, que llega a ser presidente de la Nación entre 1862 y 1868. El diario aún hoy conserva el lema con que se publicó su primer número: "tribuna de doctrina"; lema que claramente remite al imaginario de la burguesía ilustrada liberal de la época, que se autorepresenta como protagonista de lo que Habermas (1962) ha designado "esfera pública burguesa”, en la que el hombre dotado de razón, instruido, cultivado, lleva a cabo el ejercicio de la crítica, en debate entre pares, sobre intereses presentados como generales a través de un órga- 
no fundamental, la prensa ${ }^{3}$. Los propietarios actuales del diario, descendientes de Mitre, reiteran la aspiración de que el medio siga siendo "una tribuna abierta al debate intelectual", por eso conservan el lema original, y - tal como señala Julio Saguier, presidente de La Nación SA - la voluntad de ser el portavoz de un "periodismo militante" para el que la libertad de prensa constituye uno de los "baluartes estratégicos del orden constitucional argentino" (La Nación, 18 de julio de 2010).

Esta inscripción, que aún hoy declama el diario, en los que fueron principios centrales de la Modernidad, resulta indispensable para analizar el "Diálogo semanal con los lectores", ya que como veremos la escenificación discursiva que se construye en forma predominante en esta sección es la de un intercambio entre iguales, en el que se someten a juicio usos y apreciaciones sobre el lenguaje. Sin embargo, esta comunidad discursiva del diario, que como ya señalamos, representa a sectores de alto poder político, económico y cultural, no se manifiesta homogénea en sus representaciones sobre el lenguaje. Nuestro análisis nos ha permitido identificar, por una parte, una tendencia dominante fuertemente prescriptiva en los lectores, que aprecian la idea de una norma única que se corresponde con el habla de los sectores supuestamente cultos y que por lo tanto es condenatoria de todo desvío; y por otro lado, la inscripción del medio, en sus respuestas, en una ideología que critica la centralidad y unicidad de la norma, y aprecia formas que ha estabilizado el uso del lenguaje. Así el diario reproduce en sus diferencias las fuerzas contradictorias que acompañaron, durante el desarrollo de la burguesía, la constitución de diferentes imaginarios sobre la lengua, que la tradición gramatical - que se inicia en el siglo XVI y continúa hasta principios del siglo XX - ha cristalizado en las llamadas "gramáticas de Estado" y "gramáticas particulares".

\section{Las gramáticas particulares y las gramáticas de Estado}

En el marco del proceso de gramaticalización de las lenguas vernáculas - que como destaca Auroux (1994) se dieron en paralelo a los procesos de constitución de los Estados modernos - en España, tempranamente la monarquía emprendió la tarea de centralizar las políticas sobre la lengua castellana, tanto para llevar a cabo su política imperial como para consolidar la unidad y la pretendida homogeneización interna del reino. Así surgen las Ilamadas "gramáticas de Estado", es decir, gramáticas que la administración centralizada del poder adopta para acompañar sus políticas. La primera gramática de Estado del castellano es la de Nebrija, del año 1492, que resultará una pieza indispensable en el proceso de conquista de América. Posteriormente, las gramáticas de Estado serán obra de la Real Academia Española de la Lengua (RAE), creada en 1714, cuya primera Gramática de la Lengua Castellana data del año 1771. En el siglo XVIII, la gramática en España se convirtió claramente en objeto de políticas de Estado, como lo muestra la orden de Carlos III, de 1780, que obliga a que

3. La esfera pública burguesa vincula la tradición de la publicidad literaria y artística con la publicidad política y la difusión de la información económica. Estaba integrada privilegiadamente por estamentos ilustrados (funcionarios, médicos, sabios, profesores), un público raciocinante que reclama a través de la prensa en defensa de sus intereses generales (Habermas, 1962: 76). Justamente, los apelativos empleados para ubicar a los interlocutores del "Diálogo con los lectores" se identifican con estos sectores, en sus profesiones y aspiraciones. 
"en todas las escuelas del reino se enseñe a los niños su lengua nativa por la gramática que ha compuesto y publicado la Real Academia de la Lengua" (Lázaro Carreter, 1949: 176), como también el hecho de que la RAE se constituyó en la institución que decidía qué gramáticas estarían autorizadas y cuáles no para ser publicadas o reimpresas ${ }^{4}$. En cuanto a sus características, las gramáticas de Estado asumen una función fuertemente normativa y prescriptiva. Como señala Carlos Luis (1992), en Nebrija se observa ya la operación de "desafectar la gramática de la historia", es decir, se crea la ilusión de que es posible fijar la lengua en las normas que reúne "el arte de hablar bien" (tal como es definida la gramática) e independizarla de las contingencias del uso; esta operación avalará que sea llevada a cualquier parte del orbe y que se la enseñe por la unidad de la nación. Las gramáticas de la RAE buscarán llevar al extremo la tarea normativa, que será concebida como un modo de preservar la perfección que atribuyen a la lengua castellana, y que identifican con el uso de los buenos escritores, para lo cual se ocupan de "limpiarla" y "purificarla", es decir, de señalar lo que consideran vicios y deformaciones del uso, y de fijarla a través de las normas gramaticales. Esta representación de su tarea y de la lengua se manifiesta en el lema que adoptan desde 1771: "Limpia, fija y da esplendor".

Ambrosio Rabanales (1965: 263) señala el espíritu tradicionalista, conservador y el sentimiento nacionalista que caracteriza a las gramáticas de la RAE y a las de Estado, en general. Según el autor, estos se manifiestan en la defensa de la tradición literaria - que consideran la máxima expresión de la lengua, y que en el caso de la RAE remite a la literatura del Siglo de Oro español - y en la defensa del patrimonio idiomático propio, que oponen a los usos que llaman "extranjerizantes" que pondrían en peligro la pureza y la unidad del idioma.

Pero, como señala Arnoux $(2013,2008)$, en el largo proceso de conformación de los estados nacionales no solo se requirieron instrumentos lingüísticos poco sensibles a la variación, que permitieran el control y la administración jurídica y administrativa del territorio, sino que también fueron necesarios otros instrumentos que facilitaran la reflexión sobre la comunicación oral y las especificidades de la propia lengua frente a las lenguas vecinas. Estas necesidades surgen, en especial, a partir de los enfrentamientos de la nueva sociedad burguesa con el aparato monárquico, que dio lugar a distintos tipos de discursos gramaticales, entre ellos, el de las gramáticas particulares, uno de cuyos primeros exponentes es el Diálogo de la Lengua, de Juan Valdés, del año 1535. Estas obras se propusieron el objetivo de registrar los diferentes usos sociales de la lengua, destacando los usos particulares, vernáculos, propios de distintos contextos, como un modo de participar de la construcción de la nación.

Muchos de los rasgos de las gramáticas particulares entran en tensión con el centralismo de las gramáticas de Estado, como por ejemplo el reconocimiento de variedades y registros tanto orales (y de la oralidad cristalizada en refraneros) como escritos, provenientes del mundo literario, lo que las

4. Domínguez Caparrós (1976: 102) estudia las sesiones de la RAE y observa que en 1769 se autoriza la reimpresión de la Gramática de Benito Martínez Gayoso de 1743, mientras en 1778 se niega el permiso para la publicación de la Gramática Castellana de Antonio Martínez Salazar. 
llevó a poner el acento en lo arbitrario del establecimiento de un único criterio normativo (Arnoux, 2008: 211).

Una de las gramáticas particulares españolas más importante del siglo XIX es la de Vicente Salvá, de 1831, que tendrá una fuerte influencia en la Gramática de Andrés Bello, y por lo tanto en América Latina. En el Prólogo de su Gramática de la lengua castellana según ahora se habla, Salvá (1835: 19) destaca que el uso de una lengua "no está sujeto a leyes: es hijo del habla del vulgo", y que se va formando tanto a partir del roce con otros países por el comercio, los nuevos descubrimientos o las guerras, como del gusto que domina entre los literatos y en la ciencia. Su concepción del gramático es el de un "retratista" que debe copiar del uso de la lengua la mayor cantidad de "facciones" de esta (Salvá, 1835: 17). De todas formas, pese al énfasis puesto en el objetivo de descripción del uso lingüístico, las gramáticas particulares tienen también su dimensión prescriptiva ya que valoran "los usos de las personas doctas", remiten también a usos literarios y señalan "defectos" inadmisibles, como "formas anticuadas", "duras" o "carentes de fluidez", "provincialismos", "galicismos" y "neologismos”, en el caso de Salvá.

Según Arnoux (2008), estas gramáticas particulares muestran el punto de vista normativo de una burguesía que recorre el territorio desarrollando intercambios que demandan una unidad lingüística diferente de la burocrática; una burguesía que reconoce la diversidad y que es capaz de ver la presencia de voces extranjeras en la propia y de señalar las formas legítimas de su apropiación. Esta representación de la espacialidad social como heterogénea condujo a las gramáticas particulares a dar importancia al contexto y al estilo para definir la adecuación lingüística de un término o expresión (Arnoux, 2008: 216-217).

A continuación presentamos el análisis de las ideologías lingüísticas presentes en "El diálogo con los lectores" que, como ya anticipamos, reproduce rasgos propios de las gramáticas de Estado y de las particulares.

\section{El "Diálogo con los lectores"}

Un primer rasgo destacable de esta sección del diario La Nación es la elección de la escenografía conversacional - el diálogo - compartida con la construida por la considerada primera gramática particular, el Diálogo de la lengua de Juan de Valdés (escrito en 1535 y publicado recién en 1777), en la que su enunciador participa como un personaje conocedor de la lengua castellana en una conversación de sobremesa con tres italianos de la Toscana.

En su "Diálogo", el diario La Nación da respuesta o comenta las intervenciones de los lectores desde un ethos muy cercano al que presenta el personaje de Valdés, que también responde a preguntas o brinda sus opiniones ante la solicitud de Marcio, de Coriolano o de Torres. En ambos casos se escenifica una conversación y también en los dos casos solo uno de los interlocutores, Valdés y el diario, es el representado como el portador del saber sobre la lengua y con la autoridad para comunicarlo. 
Con rasgos que reconoceremos también en las intervenciones del diario, la identidad discursiva de Valdés no es propiamente la de un "gramático" sino la de quien es sensible a los usos, conoce y tiene un juicio propio sobre las distintas prácticas lingüísticas (ver ejemplo 1); y es también la de quien tiene la autoridad de expresar sus pareceres (ejemplos 1 y 2) e incluso, la de quien puede ironizar sobre los grupos sociales y sus usos del lenguaje (2) o se burla de las gramáticas normativas llamándolas "gramatiquerías" (3), aunque conoce muy bien las reglas y las comunica atendiendo a sus criterios:

(1) Marcio: ¿No sería mejor, por no caer en el inconveniente que parece sea poner artículo masculino al nombre femenino, perder la a del artículo y dezir l'arca, l'ama, l'ala?

Valdés: No me parecería mal si se usasse, pero como no se usa, yo por mí no lo osaría dezir ni escrivir. (Valdés, 1969: 69-70)

(2) Coriolano: Este último vocablo es muy nuevo para mí; no passéis adelante sin dezirme qué quiere dezir abadengo.

Valdés: Porque en la lengua castellana, de real se dice realengo "lo que pertenece al rey", quisieron los clérigos, con su acostumbrada humildad, por parecer a los reyes, que de abad se llamase abadengo "lo que pertenece al abad o abadía". (Valdés, 1969: 62-63)

(3) Torres: Vos me avéis respondido como yo merecía; proseguid adelante.

Valdés: No tengo más que proseguir, ni vosotros os podréis quexar que no os he dicho hartas gramatiquerías. (Valdés, 1969: 74)

Si, como hemos anticipado, la ideología lingüística dominante en el diario La Nación se corresponde con la tradición de las gramáticas particulares, los lectores, en cambio, predominantemente recurren a la tradición normativa desde una mirada de la lengua más cercana a la de las gramáticas de Estado. Vamos a comenzar con el análisis de las intervenciones de los lectores.

\subsection{Los lectores y las gramáticas de Estado}

En cuanto a los lectores, en estos predomina, como señalaron Miotto y Glozman (2013), una ideología lingüística prescriptivista que asociamos con las gramáticas de Estado, centradas en la lengua escrita y que se manifiesta de dos maneras.

(1) En el rechazo a cualquier forma que no sea autorizada por un centro institucional al que se le atribuye el rol de determinar "el bien hablar y el bien escribir", que para los lectores de La Nación se referencia con el diccionario de la RAE, y con otros objetos normativos de origen predominantemente español. Por ejemplo:

(4) "Joaquín Morales Solá utilizó en su columna del día 2 la 'pintoresca' palabra pentimento, a la que dio el significado de 'bosquejo', escribe [el lector] Héctor Constantinidis. 
"No encuentro esa palabra en el Diccionario de la Real Academia Española. Tampoco en la ¿Guía de vocablos y expresiones〉 del Manual de estilo de LA NACION ni en su sección «Herencia del Lacios. La ignora el Libro de estilo de El País. No figura en el Manual de español urgente, de la agencia EFE. Tampoco se la menciona en el Diccionario de dudasy problemas del idioma español, de Manuel Rafael Aragó.

¿Será que el periodista mencionado está dando trabajo al próximo Congreso de la Lengua Española?" (La Nación, 21 de febrero de 2005)

(2) La certeza de que las formas correctas se fundan en normas que consideran únicas e incuestionables. El siguiente ejemplo muestra que para el lector solo puede ser admisible una única forma "Permanentemente oigo por la radio y otros medios, y leo, expresiones como 'mañana a la mañana', 'el miércoles a la tarde', etc. Siempre tuve entendido que se decía 'por la mañana', 'por la tarde'... ¿Es así?”, pregunta desde Salto, provincia de Buenos Aires, Verónica González Kenny (14 de julio de 2008).

La enunciación asertiva inicial concluye en una pregunta (¿Es así?) que puede leerse o bien como un pedido de ratificación de que su criterio es el adecuado, o bien como una interrogación acerca de si ha estado equivocado "siempre". Pero no admite la posibilidad de que ambas formas sean posibles, adecuadas, correctas según la situación. Otro ejemplo, en este caso sobre el rechazo de un uso regional del "hasta" en México, muestra la descalificación y la crispación del hablante ante un uso que considera apartado de "la" norma y por lo tanto inadmisible:

(5) Nos confunde ver a gente de esas regiones diciendo cosas tales como "la tienda abre hasta el lunes" [...] Me encantaría saber su opinión sobre si existe alguna posibilidad de resistir tal barbarismo o si deberemos resignarnos a que, tal vez próximamente, la Real Academia acepte ese uso inverso para la palabra arriba mencionada. ¿Está justificada mi irritación? ¿Coincide usted conmigo en que el uso de hasta al revés suena muy vulgar? (La Nación, 22 de noviembre de 2004)

\subsection{La ideología lingüística del diario y las gramáticas particulares}

En cuanto a los comentarios que realiza la Prof. Castro como voz autorizada por el medio, identificamos los siguientes rasgos que caracterizaron también a las gramáticas particulares.

(1) Reconocimiento de variedades y registros diferentes, tanto de la lengua oral como de la escrita, basado en la aceptación del uso como criterio de corrección. Ante la observación sobre el uso abusivo del diminutivo, que realiza un lector recién llegado al país después de 37 años de ausencia, que concluye ironizando: "Le voy a pedir el favorcito de que me conteste esta preguntita: ¿qué está pasando con nuestro idioma?", el diario, que titula el comentario "Lo bueno en frasco chico", responde del siguiente modo:

5. En los ejemplos, todos los subrayados son nuestros. 
(6) Es posible que ese uso afectado del diminutivo esté más extendido hoy que hace treinta y siete años, especialmente en ciertos ámbitos comerciales, pero esto puede ser también una impresión causada por el hecho de que, aunque el lector no haya cortado su relación con el país durante su larga ausencia, seguramente mantuvo el contacto sobre todo a través de la lengua escrita, y el diminutivo, a menudo con valor afectivo, es mucho más frecuente en el lenguaje oral.

El uso del diminutivo con valor afectivo es muy antiguo. En su célebre poema sobre la muerte del pájaro (pajarito, diríamos nosotros) de Lesbia, dice Catulo: "iOh pobrecito pájaro! Por tu causa, ahora están rojos, hinchaditos por el llanto, los ojitos de mi niña". Este empleo afectivo supone cercanía, intimidad. Por otra parte, el diminutivo puede ser también un recurso eufemístico, para decir las cosas más suavemente, con más delicadeza. Entonces, si una persona quiere conseguir algo de otra, por ejemplo si un vendedor quiere conseguir que un cliente le compre, con el diminutivo se pone más cerca del cliente y, a la vez, muestra sus buenos modales. Por supuesto, esta afectación puede resultar molesta y de muy mal gusto.

Pero ese uso afectado del diminutivo no es tampoco novedad. Los lectores más grandes recordarán aquel chiste que circulaba sobre un gobernador al que habían hecho fama de bruto. El hombre, para demostrar buena educación, pedía todo en diminutivo, hasta que alguien le advirtió que esa afectación era una vulgaridad. Entonces, cuando en una reunión le ofrecieron un bocado que no deseaba, respondió: «Gracias, no tengo apeto». La anécdota, aunque falsa, es sin embargo ilustrativa de la afectación en el habla de ciertas personas que querían pasar por refinadas hace ya más de cincuenta años. (La Nación, 4 de abril de 2005)

Así, el diario, a diferencia del lector, reconoce distintos valores del diminutivo (afectivo, eufemístico, afectado); historiza su uso desde la antigüedad clásica en diferentes géneros, entre ellos el poético (que es siempre legitimante para esta comunidad); propone una interpretación de la percepción del hablante causada por las diferencias entre oralidad - valorada ya desde el título del comentario que alude a un refrán - y escritura.

Un aspecto interesante para destacar en este ejemplo - que consideramos una regularidad en las intervenciones del diario - es que el reconocimiento de las variedades está asociado a la construcción de una distancia entre la dupla yo/tú en diálogo y la no persona de la que se habla, a la que se caracteriza por su modo de hablar como "carente de educación", "vulgar", "no refinada", "bruto". La comunidad, aun en su heterogeneidad de ideologías lingüísticas, se auto representa como homogénea sociolectalmente y en sus apreciaciones estéticas, por lo que constantemente el diario construye una complicidad con el lector ("Por supuesto, esta afectación puede resultar molesta y de muy mal gusto").

(2) Así como las gramáticas particulares criticaron la centralización de la norma (Luis, 1997; Arnoux, 2013, entre otros) y a las instituciones que pretendían imponerla, el diario La Nación critica frecuentemente a la RAE, por razones varias. O bien porque no reconoce que por el uso ciertas formas deberían admitirse. Por ejemplo, critica que se admita "cantilena" por su etimología y no "cantinela", 
cuando se trata de una metátesis propia del uso; o bien porque no mantiene criterios racionales y coherentes ni siquiera a lo largo de la misma obra. Este último caso es ilustrado por el siguiente ejemplo, en el que la Academia al ser evaluada como desprolija, como quien de pronto recuerda u olvida reglas, es deslegitimada en su pretendida autoridad centraı. Sostiene Lucila Castro:

(7) [...] Pero el ejército de neologismos y extranjerismos que se han abierto paso últimamente entre las líneas del diccionario oficial es responsable de cierta desprolijidad en la redacción de los artículos y en las grafías.

Por ejemplo, en la edición de 1984 del Diccionario entró la voz samuray. Sí, escrita con i griega como ay y caray, dado que en español las palabras terminadas en diptongo o triptongo en i se escriben con i griega. Pero por entonces los escribidores ya hacía rato que venían escribiendo la palabreja samurái. O samurai, porque casi nunca le ponían la tilde que corresponde a una voz aguda terminada en vocal. [...] La Academia misma, en 1956, la había escrito así, sin tilde, como "voz japonesa".

En 1984 se acordó de la regla y la escribió con i griega, pero al año siguiente, en el Diccionario manual, al parecer se asustó de lo que podrían decir los escribidores y, sin comprometerse, propuso el doblete samurái o samuray. Pero en 1992 dejó en el DRAE sólo la forma regular, con i griega. Después de tanto vacilar, en la última edición, de 2001, no tuvo mejor idea que entrar samurái, contra la regla ortográfica, y remitir samuray a esa entrada.

Lo curioso es que desde 1992 tiene registrado también bonsái, así, sin vacilar, solamente como bonsái, sin acordarse de la grafía regular bonsay. De modo que no sólo no respetó sus propias reglas sino que usó criterios diferentes en dos casos iguales. (La Nación, 13 de septiembre de 2004)

(3) Esta falta de coherencia de la que se acusa a la RAE es tomada, en otros casos, como criterio para fijar el límite de lo aceptable. Aún cuando en esta columna se hace una apología del uso, la representación de la lengua "correcta" marca límites que no pueden transgredirse. Uno de ellos es el que se designa como "racionalidad del sistema". Por ejemplo, en la respuesta a la consulta sobre el uso mejicano de la preposición "hasta", señala taxativamente un principio que el uso no estaría respetando: "En ningún sistema de signos un signo puede significar una cosa y a la vez su opuesta" (22 de noviembre de 2004).

(4) Otro elemento que se utiliza para fijar los límites de lo aceptable en el uso es el rechazo de los extranjerismos y la tendencia a propiciar la castellanización. Como ya señalamos, este también es un punto en común con las gramáticas particulares que defendieron la lengua nacional. Son múltiples los ejemplos que ilustran este rasgo, que a veces es compartido con los lectores como en el ejemplo que sigue:

(8) “[...] le hago llegar mi extrañeza por el pertinaz empleo del término inglés default, horrorosa palabra que parece dar más importancia a quien la utiliza, incluyendo al prestigioso diario en el que usted escribe. Ya sé que es una causa casi perdida, aunque aún quedamos quienes 
moriremos con las botas puestas en la defensa del buen uso del castellano. Por este motivo, confío en que usted eche una mano para dar un repaso a los nuevos y pedantes bárbaros y decirles cuál es la expresión castellana que se debe utilizar", escribe Agustín Fernández desde Madrid.

No está muerto quien pelea, señor Fernández. Habla usted de una causa "casi" perdida, pero, como decía mi madre, de "casi" nadie se muere. Sin embargo, es difícil. Vea usted hasta dónde ha llegado la ridiculez que no hace mucho, tal vez por descuido, se empleó la expresión "cesación de pagos" y el redactor se creyó obligado a aclararla. ¡Y la aclaró escribiendo entre paréntesis el término inglés default! (La Nación, 18 de octubre de 2004)

Un rasgo compartido entre lectores y medio - que remite a una característica claramente ilustrada que ambos buscan poner en escena - es la atribución al lenguaje de una función primordialmente informativa, razón por la cual la precisión en los modos de nombrar el mundo y de escribir los nombres de las cosas es considerada un requisito imprescindible. Desde este punto de vista, los modos de nombrar revelan el conocimiento del mundo y deben ser respetados porque, de algún modo, se los considera portadores de la esencia de la cosa nombrada. Lo interesante en esta comunidad discursiva es que esa precisión es objeto de preocupación y de control por parte del lector que llega a elaborar una queja por escrito e instala el detalle de una letra como tema del diálogo para señalar errores, particularmente en lengua extranjera, en el modo en que se nombran topónimos lejanos o el uso de un hiperónimo en lugar de un nombre propio, o en el empleo de un léxico impreciso. El "Diálogo" del 6 de septiembre de 2004 ilustra este rasgo en dos de sus comentarios:

(9) El doctor Enrique Martín Pouyssegur, de Mar del Plata, considera que las enmiendas de plana son siempre antipáticas, pero, dice, «la lealtad intelectual, o cultural, obliga a estas correcciones». Escribe el lector:

"El 16 de agosto, en un artículo a propósito de la visita del Papa a Lourdes, bajo el título "La visión de una bella Señora”, se describen las apariciones de la Virgen a Santa Bernadette Soubirous, entre febrero y julio de 1858, "en una gruta a la vera del río Gave" (sic), siendo que gave (de gabe en patois bearnés) es un término genérico con el cual se designan en el Béarn y en la Bigorre los torrentes que nacen en los Pirineos centrales, como el gave de Pau, que es el que corre al pie de la gruta de las apariciones, nacido en el circo glaciar de Gavarnie (Hautes-Pyrenées), que riega en su curso Lourdes y Pau, antes de alcanzar la margen izquierda del Adour, en el que desemboca.

Por su parte, el doctor Juan José Cresto, en el interesante bosquejo biográfico "San Martín: el último acto", cuenta la visita del Libertador, en el verano europeo de 1850, para paliar sus dolores reumáticos, a las termas de "Engheim" (sic). La estación termal a la que sífue a buscar alivio el Padre de la Patria, es Enghien-les-Bains, comuna de Seine-Oise, de la cual la prefectura es Versailles, en los alrededores de Pontoise, sobre el lago de Enghien, a no mucha distancia de París, célebre por sus aguas sulfurosas". 
En una columna sobre los sesenta años de la liberación de París, publicada el 24 de agosto, se lee: "Hasta que sonaron los primeros vítores y el primer corcho de algún beaujolais atesorado para el momento tan esperado". Resulta poco probable - escribe Hugo Perini - que haya acontecido lo que se dice del descorche. Por dos motivos: el primero es que el beaujolais no es un vino espumante y el segundo es que se trata de un vino joven, no de guarda, y por eso se recomienda siempre beberlo dentro del año de su puesta en botella. (La Nación, 6 de septiembre de 2004)

Esta exigencia de precisión asocia la función informativa con una concepción del lenguaje como transparente; de ahí que la más mínima distorsión léxica, gráfica o normativa sea un índice de una percepción distorsionada del mundo. Asimismo, los errores señalados contribuyen a dar cuenta de un ethos que se exhibe como hiperculto, mundano y cosmopolita.

\section{Conclusiones}

A partir del análisis hemos mostrado que las ideologías lingüísticas de lectores y del medio que responde no son totalmente homogéneas: en los lectores predomina el criterio normativo prescriptivo mientras que el medio se muestra defensor de variedades propias del uso, de la existencia de normas diferentes para la oralidad y la escritura, entre otras. Así, ambos interlocutores ponen en escena ethos (Maingueneau, 2002) distintos aunque comparten el rasgo "hiperculto". Sin embargo, mientras en los lectores predomina el ethos crispado por las deformaciones de la norma que evalúan como única, en las respuestas del medio se exhibe un ethos más flexible, más amplio en sus criterios y en sus conocimientos que le permiten hacer evaluaciones más complejas.

En el análisis también hemos buscado historizar estos posicionamientos ante el lenguaje y hemos trazado continuidades entre las gramáticas de Estado y las posiciones de los lectores como también entre las gramáticas particulares y el medio. Sin embargo, es necesario destacar la doble paradoja que plantea este caso presente frente al pasado: por un lado, el hecho de que no es una institución estatal a la que recurre el lector para hacer sus consultas, sino a un medio privado que es reconocido como un referente para los miembros de la comunidad del diario ${ }^{6}$. Ni por parte de los lectores ni por parte del diario hay referencia alguna a instrumentos o instituciones normativas estatales, lo que revela que la representación para ambos es que no hay voz normativa legítima proveniente del Estado nacional argentino y que el interlocutor local - capaz de canalizar dudas, indicar la validez o no de una observación de un lector o dar explicaciones sobre la lengua - es el medio privado. Esta jerarquización del diario como referente para la consulta sobre cuestiones del lenguaje es reforzada por el mismo periódico no solo a través del Manual de Estilo, en el que explícitamente había adoptado un rol normativista, sino en las propias páginas del diario, a través de esta sección "Diálogo con los

6. La Academia Argentina de Letras tiene habilitado un número telefónico al que puede llamarse para hacer consultas sobre el lenguaje, pero sin embargo, esta institución no es mencionada en ningún momento en la sección, en el período estudiado. 
lectores", destinada a la reflexión sobre el lenguaje en la que se escenifica un diálogo entre el medio y el lector. Cabe destacar que en ningún otro diario argentino de alcance nacional se escenifica este tipo de diálogo para abordar cuestiones relativas al lenguaje.

Por otro lado, pensamos que este espacio discursivo otorga al diario un aire de progresismo crítico ya que se revela más avanzado en sus posiciones que sus lectores, lo cual resulta también paradojal ya que se trata de un posicionamiento que tuvo ese valor hace por lo menos un siglo, asociado a la importancia que ciertos sectores ilustrados otorgaron a la variedad en el proceso de constitución de las democracias burguesas ${ }^{7}$. Hoy ese "progresismo" resulta escaso en la medida en que sigue concibiendo la racionalidad sistémica para juzgar la corrección y sigue fijando el límite de los usos aceptables en las variedades sociolectales correspondientes a los sectores cultos. Así, los usos propios de diversos grupos sociales siguen siendo rechazados normativa y estéticamente. Hay que señalar también que la defensa de lo nacional frente a lo extranjero, hoy, evita contemplar la problemática lingüística que deriva de la integración regional, como proyecto que atienda a los derechos e intereses de las mayorías.

7. Lope Blanch (1969: 30), entre otros, destaca que ya en el siglo XVI Valdés consideraba que "la autoridad en materia de corrección lingüística corresponde al uso siempre y cuando cuente éste con el consenso de los hombres buenos, de los hombres cultos". 


\section{Bibliografía}

Arnoux, Elvira Narvaja de (2000), "La Glotopolítica: transformaciones de un campo disciplinario", en Lenguajes: teorías y prácticas, Buenos Aires, Gobierno de la Ciudad de Buenos Aires, Instituto Superior del Profesorado, p. 95-109.

Arnoux, Elvira Narvaja de (2008), Los discursos sobre la nación y el lenguaje en la formación del Estado (Chile, 1842-1862): estudio glotopolítico, Buenos Aires, Santiago Arcos.

Arnoux, Elvira Narvaja de (2012), "Los estudios del discurso y la Glotopolítica: entrevista”, en Zapata O. Londoño (ed.), Los Estudios del Discurso: miradas latinoamericanas I, Ibagué (Colombia), Universidad de Ibagué, p. 149-175.

Arnoux, Elvira Narvaja de (2013), "Esbozos de un archivo de la diversidad lingüística en dos textos gramaticales renacentistas: el Diálogo de la lengua de Juan de Valdés y el Arte grande de la lengua castellana de Gonzalo Correas", en Elvira Arnoux y Pilar Roca (eds.), Del español y el portugués: lenguas, discurso, enseñanza, João Pessoa, Editora UFPB, p. 285-326.

Arnoux, Elvira Narvaja de, María Imelda Blanco y Mariana di Stefano (1999), "Las representaciones de la lengua y de la prensa en los manuales de estilo periodísticos argentinos", en Elvira Arnouxy Roberto Bein (eds.), Prácticas y representaciones del lenguaje, Buenos Aires, Eudeba, p. 175-190.

Auroux, Sylvain (1994), La révolution technologique de la grammatisation, Lieja, Mardaga.

Beacco, Jean-Claude (1999), "L'actualité des sciences astronomiques dans les quotidiens: le gai savoir", en Jean-Claude Beacco (ed.), L'astronomie des médias: analyses linguistiques de discours de vulgarisation, París, Presses de la Sorbonne Nouvelle, p. 199-226.

Bello, Andrés (1995), "Gramática de la la lengua castellana destinada al uso de los americanos", en Obras completas, tomo cuarto, tomo cuarto, $3^{a}$ ed., Caracas, La Casa de Bello.

Del Valle, José (2007), “La RAE y el español total: esfera pública o comunidad discursiva”, en José Del Valle (ed.), La lengua ¿patria común?, Madrid, Iberoamericana, p. 81-96.

Domínguez Caparrós, José (1976), “La Gramática de la Academia del Siglo XVIII”, Revista de Filología Española, nº 58, p. 81-108.

Habermas, Jürgen (1962), Historia y crítica de la opinión pública, Barcelona, Gustavo Gili.

Kroskrity, Paul V. (2000), "Regimenting languages: language ideological perspectives", en Paul V. Kroskrity (ed.), Regimes of language: ideologies, polities and identities, Santa Fe, School of American Research Press, p. 1-34.

Lázaro Carreter, Fernando (1949), “Las ideas lingüísticas en España durante el siglo XVIII”, Revista de Filología Española, anejo XLVIII.

Lope Blanch, Juan M. (1969), “Introducción biográfica y crítica”, en Juan de Valdés, Diálogo de la lengua, Madrid, Clásicos Castalia, p. 7-34. 
Luis, Carlos (1992), "Incoincidencias: Valdés, Nebrija”, Signo y Seña, n 1, Buenos Aires, p. 13-30.

Maingueneau, Dominique (2002), "Problèmes d'ethos", Pratiques, no 113-114, p. 55-67.

Martínez Gayoso, Benito (1743), Gramática de la Lengua Castellana reducida a breves reglas y fácil método para la instrucción de la juventud, Madrid, Juan de Zúñiga.

Milroy, James y Leslie Milroy (1999), Authority in Language: Investigating Standard English, London, Routledge.

Miotto, Carla y Mara Glozman (2013), "Conocimiento lingüístico y discurso normativo en la prensa argentina actual. La variedad culta según los lectores del diario La Nación”, en Guiomar Ciapuscio (ed.), Variedades del español en la Argentina: estudios textuales y de semántica léxica, Buenos Aires, EUDEBA, p. 13-31.

Rabanales, Ambrosio (1965), "La gramática de la Academia y el estado actual de los estudios gramaticales", Boletín de Filología de Chile, Universidad de Chile, vol. 17, p. 261-280.

Salvá, Vicente (1835), Gramática de la lengua castellana según ahora se habla, Valencia, 2da. Edición. [1ed., 1831.]

Valdés, Juan de (1969 [1535]), Diálogo de la lengua, edición, introducción y notas de Juan M. Lope Blanch, Madrid, Clásicos Castalia. 